\title{
Carburization of Steels in a Circulatory System Using Water-Gas Atmospheres
}

\author{
Y.C. Chen and G.S. Lu
}

\begin{abstract}
In order to economize on raw materials for producing controlled atmospheres and to avoid the air pollution caused by exhausted atmospheres, the feasibility of carburizing steel by using recirculated water-gas atmospheres was investigated. Water-gas was generated in a closed system and an open system respectively, and steel samples were heated under the water-gas atmospheres. Based on the heating results of steel, the relationship between the generation conditions of water-gas and its carburizing behavior was examined. In addition, the carburizing results as well as the charcoal consumption for both systems are compared with each other.
\end{abstract}

\section{Introduction}

The authors have made a series of studies on watergas atmospheres in recent years [1-4]. In Ref. [1] they proposed a method to prepare controlled atmospheres for the heat treatment of steel by adding water-gas, generated by reacting water vapor with hot charcoal, to commercial grade nitrogen, and examined the influence of water-gas generation conditions and addition level on the carbon potential of such blends. It was concluded that the carbon potential of the blends increases with increasing the volume fraction of water-gas. So, blends to be used for carburizing must contain a large amount (generally over $40 \%$ ) of water-gas.

However, to produce carburizing atmospheres by this method, two problems arise: (a) rapid consumption of charcoal and (b) the exhausted atmosphere, which contains large amounts of $\mathrm{CO}$ and $\mathrm{H}_{2}$, not only leading to a waste of energy but also resulting in air pollution.

Essentially, the carbon potential of the abovementioned water-gas atmosphere comes from the hot charcoal, which reacts with water vapor to form water-gas according to the following reactions (1) and (2):

Y.C. Chen, Associate Professor, and G.S. Lu, Graduate Student, are with National Taiwan University, Taipei 10764, Taiwan, R.O.C.

$$
\begin{gathered}
\mathrm{H}_{2} \mathrm{O}+\mathrm{C} \rightarrow \mathrm{CO}+\mathrm{H}_{2} \\
2 \mathrm{H}_{2} \mathrm{O}+\mathrm{C} \rightarrow \mathrm{CO}_{2}+2 \mathrm{H}_{2}
\end{gathered}
$$

where $\mathrm{C}$ represents the carbon contained in charcoal. Water-gas has a definite equilibrium composition at a given temperature and a given pressure. For example, at $900^{\circ} \mathrm{C}$ and $1 \mathrm{~atm}$, the equilibrium composition of water-gas is $48.6 \% \mathrm{CO}, 49.3 \% \mathrm{H}_{2}, 0.7 \%$ $\mathrm{CO}_{2}, 0.9 \% \mathrm{H}_{2} \mathrm{O}$, and minor amounts of $\mathrm{CH}_{4}$ [1]. When steel is carburized in a water-gas atmosphere, the two most important carburizing reactions are as follows:

$$
\begin{gathered}
\mathrm{H}_{2}+\mathrm{CO} \rightarrow[\mathrm{C}]+\mathrm{H}_{2} \mathrm{O} \\
2 \mathrm{CO} \rightarrow[\mathrm{C}]+\mathrm{CO}_{2}
\end{gathered}
$$

where [C] represents the carbon dissolved in austenite. After the carburizing reactions take place, the contents of $\mathrm{H}_{2}$ and $\mathrm{CO}$ will decrease and the contents of $\mathrm{H}_{2} \mathrm{O}$ and $\mathrm{CO}_{2}$ will increase. As a result, the carbon potential of water-gas will decrease. If the watergas with a decreased carbon potential repasses through the hot charcoal layer, the $\mathrm{H}_{2} \mathrm{O}$ and $\mathrm{CO}_{2}$ in watergas will react with charcoal according to reactions (1) and (5) to form $\mathrm{CO}$ and $\mathrm{H}_{2}$. So, the water-gas will recover its carbon potential.

$$
\mathrm{H}_{2} \mathrm{O}+\mathrm{C} \rightarrow \mathrm{CO}+\mathrm{H}_{2}
$$




$$
\mathrm{CO}_{2}+\mathrm{C} \rightarrow 2 \mathrm{CO}
$$

where $C$ represents the carbon contained in charcoal. Therefore, if the water-gas atmosphere is used to carburize steel repeatedly in a closed circulative system, it can keep a constant carbon potential through reactions (1) and (5). Moreover, the amounts of $\mathrm{CO}_{2}$ and $\mathrm{H}_{2} \mathrm{O}$ in the used water-gas atmosphere are relatively small; therefore, the consumption of charcoal through reactions (1) and (5) is little, compared with that of generating water-gas in an open system by reacting water vapor with hot charcoal according to reactions (1) and (2).

The objective of this study is to investigate the feasibility of recycling the water-gas atmosphere after carburizing steel. First, water-gas generated in a closed circulative system, and steel samples were heated in such water-gas atmosphere under some specific conditions. Then, based on the carbon content and hardness distribution in the surface layer of treated samples and the variation of water-gas composition, both the stability of water-gas atmosphere in the closed system and its carburizing behavior are elucidated. Finally, the results of carburization employing watergas atmospheres in the open system and closed system are compared with each other, and the benefits of the closed system on steel carburizing are shown.

\section{Experimental Method}

The schematic diagram of the experimental apparatus is shown in Figure 1. The water vapor from the heated flask reacts with the hot charcoal in the charcoal furnace to form water-gas. The oxygen partial pressure of the water-gas can be determined by passing it through the oxygen testing furnace, which contains an oxygen sensor. After flowing through an adjustable flowmeter, the water-gas was introduced

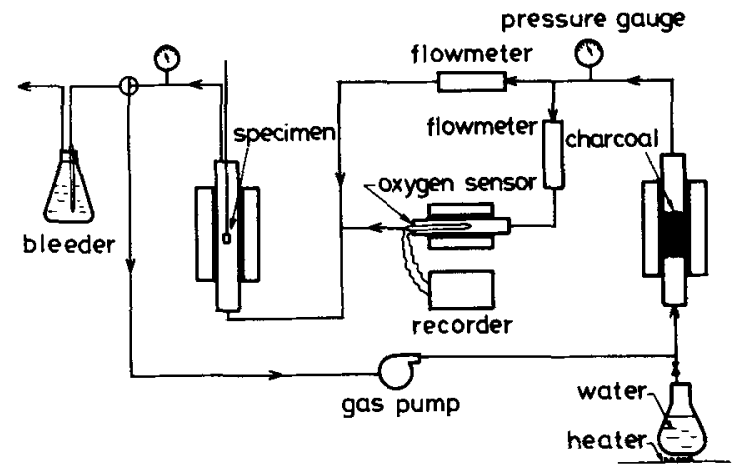

Fig. 1. Experimental apparatus. into the specimen furnace, in which steel samples were heated. For comparison, two systems were adopted in this experiment, namely an open system and a closed system. For the open system, the watergas flowing out from the specimen furnace was exhausted to the air through a bleeder, whereas for the closed system, it was passed again through the charcoal furnace with a gas pump to react with the hot charcoal again. The circulation rate of water-gas in the closed system can be regulated by controlling the rpm of the gas pump or adjusting the needle valve of the flowmeter.

The charcoal furnace, the specimen furnace, and the oxygen testing furnace all are resistance heated furnaces. A ceramic tube, with an inner diameter of $30 \mathrm{~mm}$ and a length of $1000 \mathrm{~mm}$, was placed at the center of the charcoal furnace. Inside the tube, charcoal of $8 \sim 16$ mesh, with a depth of $200 \mathrm{~mm}$, was filled at the middle part of the charcoal furnace, where the temperature distribution is uniform. The oxygen sensor uses a $\mathrm{ZrO}_{2}$ tube as a solid electrolyte and air as a reference gas. When an oxygen partial pressure was measured, the temperature of the oxygen testing furnace was kept at $950^{\circ} \mathrm{C}$ and the electromotive force developed at the oxygen sensor was recorded with a minivolt recorder. A ceramic tube, $1000 \mathrm{~mm}$ long $x$ $30 \mathrm{~mm}$ 1.D., was installed at the center of the specimen furnace as a heating chamber of steel samples.

Table 1. Experimental Conditions

\begin{tabular}{|c|c|c|c|c|c|}
\hline \multirow[b]{2}{*}{ Condition } & \multicolumn{2}{|c|}{$\begin{array}{c}\text { Generation Condition } \\
\text { of Water-Gas } \\
\end{array}$} & \multicolumn{3}{|c|}{$\begin{array}{c}\text { Steel Sample } \\
\text { Heating Condition }\end{array}$} \\
\hline & $\begin{array}{l}\text { Charcoal } \\
\text { Temp. } \\
\left({ }^{\circ} \mathrm{C}\right)\end{array}$ & $\begin{array}{c}\text { Generation } \\
\text { Rate } \\
\text { (cc/min) }\end{array}$ & Sample & $\begin{array}{l}\text { Temp. } \\
\left({ }^{\circ} \mathrm{C}\right)\end{array}$ & $\begin{array}{l}\text { Time } \\
(\min )\end{array}$ \\
\hline 1 & 900 & 260 & SPCE & 900 & 1,9 \\
\hline $2^{*}$ & $\begin{array}{c}850,900 \\
950\end{array}$ & 120 & 一 & - & - \\
\hline $3^{*}$ & 900 & $\begin{array}{c}120,260 \\
330,480 \\
580\end{array}$ & SPCE & 900 & $1-15$ \\
\hline 4 & $\begin{array}{l}800,850 \\
900,950\end{array}$ & 260 & SPCE & 900 & $1-15$ \\
\hline $5^{*}$ & 900 & 260 & SPCE & $\begin{array}{c}850,900 \\
950\end{array}$ & $1-15$ \\
\hline $6^{*}$ & 990 & $\begin{array}{c}120,260 \\
330\end{array}$ & $\begin{array}{l}\text { pure iron } \\
\text { SAE } 1020\end{array}$ & 900 & $\begin{array}{c}60,180 \\
300\end{array}$ \\
\hline 7 & $\begin{array}{l}800,850 \\
900,950\end{array}$ & 260 & $\begin{array}{l}\text { pure iron } \\
\text { SAE } 1020\end{array}$ & 900 & 180 \\
\hline $8^{*}$ & 950 & $\begin{array}{l}120 \\
260\end{array}$ & $\begin{array}{l}\text { pure iron } \\
\text { SAE } 1020\end{array}$ & 930 & $\begin{array}{c}60,180 \\
300\end{array}$ \\
\hline $9^{*}$ & $\begin{array}{l}850 \\
900\end{array}$ & 180 & - & - & - \\
\hline
\end{tabular}

\footnotetext{
${ }^{*}$ Experiments were conducted in both closed and open systems.
} 
All specimens were suspended at the middle of the furnace for heating.

Table 1 summarizes the experimental conditions, indicating the conditions for generating water-gas and heating specimens. Steel samples used include three types: (a) Extreme low carbon steel foil, with a thickness of $0.05 \mathrm{~mm}$, JIS-SPCE $(0.05 \%$ C, $0.008 \%$ $\mathrm{Si}, 0.28 \% \mathrm{Mn}, 0.23 \% \mathrm{P}, 0.022 \% \mathrm{~S})$. The specimen had dimensions of $20 \times 10 \times 0.05 \mathrm{~mm}$. This type of specimen was used to test the equilibrium carbon content of steel (or the carbon potential of the atmosphere) while it was heated in the water-gas atmosphere. (b) Disk shaped pure iron specimen $(0.015 \%$ C, $0.005 \% \mathrm{Si}, 0.068 \% \mathrm{Mn}, 0.010 \% \mathrm{P}, 0.008 \%$ S) with a thickness of $5 \mathrm{~mm}$ and a diameter of 12 $\mathrm{mm}$, (c) Disk shaped low carbon steel SAE 1020 specimen $(0.21 \% \mathrm{C}, 0.45 \% \mathrm{Mn}, 0.04 \% \mathrm{P}, 0.05 \% \mathrm{~S})$. The specimen had the same dimensions as the pure iron specimen. Both were used to test the amount of carbon carburized, and the hardness distribution in the surface layer of steel after carburizing and quenching.

The weight change of a specimen after heating in the water-gas atmosphere can be considered to be the weight change of the carbon in the specimen if no oxidations take place. In this experiment, the carbon content of SPCE and the amount of carbon carburized into a specimen of pure iron or SAE 1020 after heating are calculated by using the following equations:

Carbon content of SPCE, \%

$$
=\frac{0.057 \times W_{1}+100 \times\left(W_{2}-W_{1}\right)}{W_{2}}
$$

The amount of carbon carburized into pure

$$
\text { iron or low carbon steel, } \mathrm{mg} / \mathrm{cm}^{2}=\frac{W_{2}-W_{1}}{A}
$$

where

$$
\begin{aligned}
W_{1} & =\text { the original weight of specimen } \\
W_{2} & =\text { the weight of specimen after heating } \\
A & =\text { the surface area of specimen }
\end{aligned}
$$

\section{Results}

\section{Stability of Water-Gas Atmospheres During Circulation}

Carbon potential stability. In order to understand if the carbon potential of water-gas is stable, ex- periments were performed according to condition 1 in Table 1. One piece of SPCE specimen was put into the specimen furnace for heating every $10 \mathrm{~min}$ interval after the circulation of water-gas atmospheres. Heating time is 1 or $9 \mathrm{~min}$. The carbon content of specimens after heating is illustrated in Figure 2 . The carbon content of the specimen heated for 1 $\min$ is $0.42 \%$ to $0.49 \%$, and that heated for $9 \mathrm{~min}$ is $1.16 \%$ to $1.24 \%$. From this figure, it is clear that the carburizing behavior of the water-gas atmosphere is rather stable during the period of circulation in the closed system.

Oxygen content stability. Water-gas was generated in accordance with condition 2 in Table 1 , and its

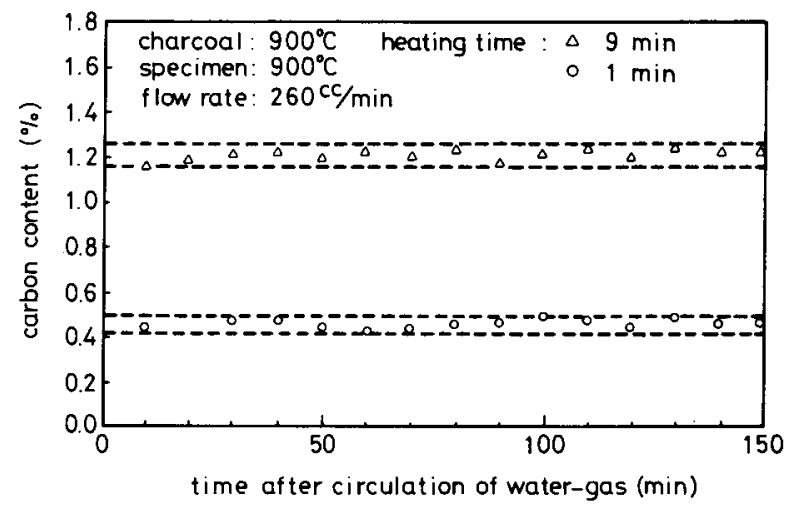

Fig. 2. Carbon content of SPCE after heating under the circulative water-gas atmosphere for 1 and $9 \mathrm{~min}$, respectively.

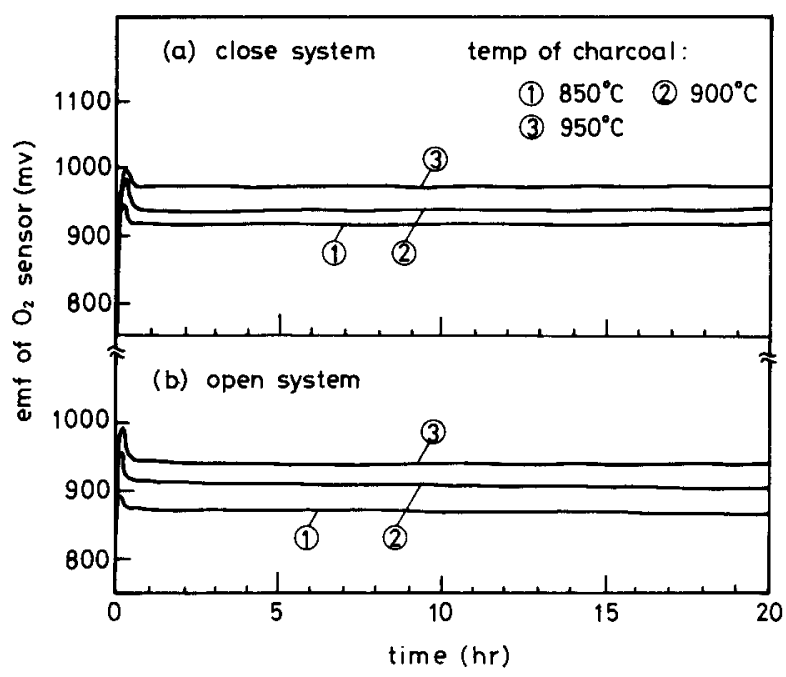

Fig. 3. Variation of the electromotive force developed at oxygen sensor while it was detecting the oxygen partial pressure of water-gas generated in (a) closed system and (b) open system. 
oxygen partial pressure was determined with an oxygen sensor by passing it through the oxygen testing furnace. The partial pressure of oxygen is correlated with the electromotive force (EMF)(millivolts) developed at the oxygen sensor; that is, the lower the oxygen partial pressure, the higher the EMF [5]. Figures 3(a) and (b) show the EMF as a function of time from the moment that water-gas was introduced into the oxygen testing furnace for the closed system and open system, respectively. From these curves, it is known that the EMF for either system reaches its individual steady value in $20 \mathrm{~min}$ and does not change significantly thereafter. This indicates that the oxygen partial pressure of the water-gas generated in either system is quite stable.

\section{Equilibrium Carbon Content of Steel Heated under the Water-Gas Atmosphere in the Closed System}

Influence of the circulation rate of water-gas on the equilibrium carbon content of steel. Experiments were conducted in the closed system according to condition 3 in Table 1; that is, SPCE specimens were heated in water-gas atmospheres, with various circulation rates, at $900^{\circ} \mathrm{C}$ for period from 1 to $15 \mathrm{~min}$. The relationships between heating time and carbon content of specimens heated are indicated by the solid lines in Figure 4. For a given circulation rate, carbon content of the specimen increases with time, and reaches some equilibrium level after about 10 min of heating. Comparing curves in this figure, we know that the greater the circulation rate of watergas, the higher the equilibrium carbon content of steel.

Influence of charcoal temperature on the equilibrium carbon content of steel. In order to understand the

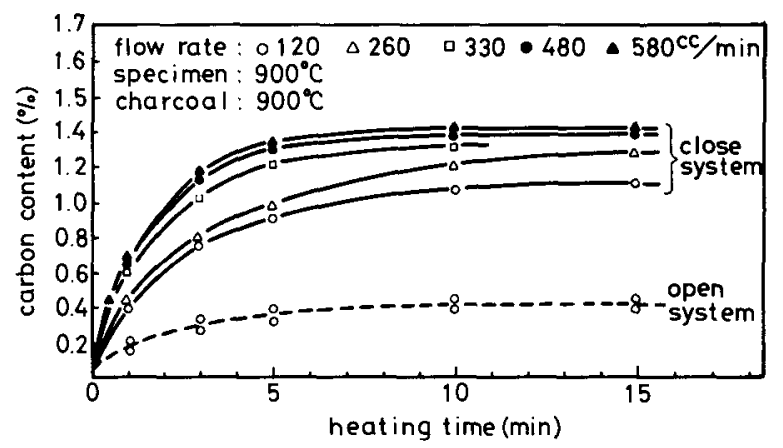

Fig. 4. Relationship between time and carbon content for SPCE heated at $900^{\circ} \mathrm{C}$ under the water-gas atmosphere with various flow rates.

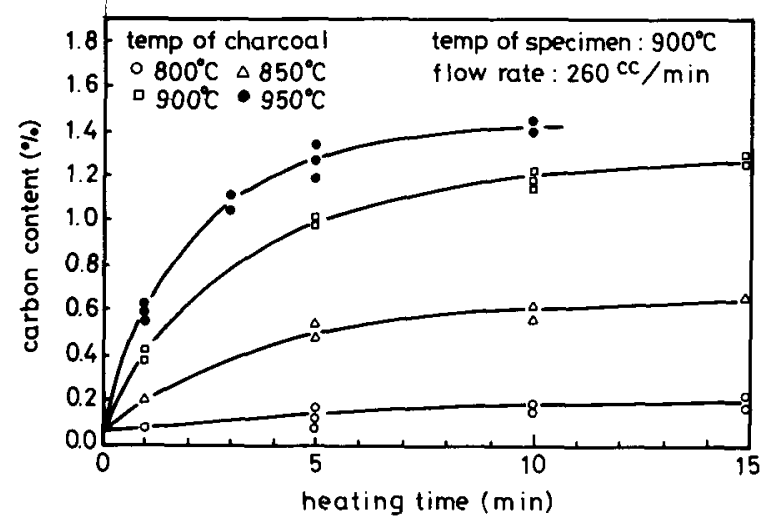

Fig. 5. Relationship between time and carbon content for SPCE heated at $900^{\circ} \mathrm{C}$ under the water-gas atmosphere generated at various charcoal temperatures in the closed system.

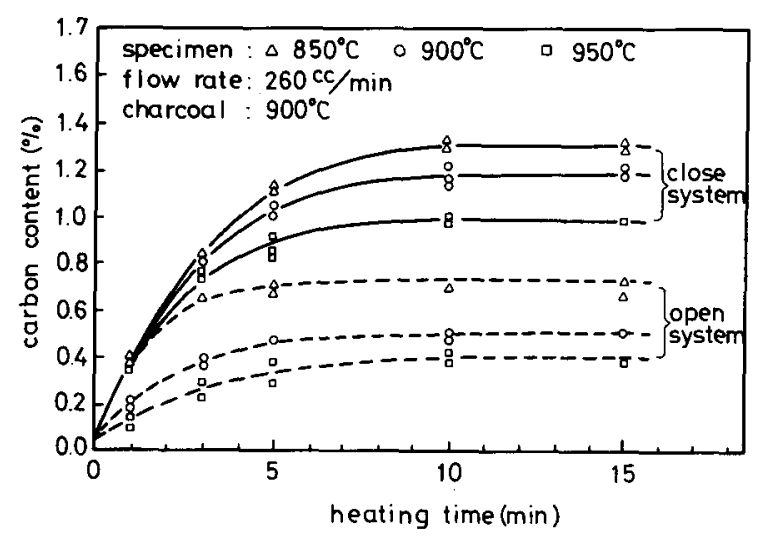

Fig. 6. Relationship between time and carbon content for SPCE heated at various temperatures under the watergas atmosphere.

relationship between charcoal temperature and the equilibrium carbon content of steel, experiments were performed in the closed system according to condition 4 in Table 1. The result, as shown in Figure 5, indicates that the higher the charcoal temperature, the higher will be the equilibrium carbon content of steel or the carbon potential of the water-gas.

Influence of heating temperature on the equilibrium carbon content of steel. In order to understand the effect of temperature on the equilibrium carbon content of steel heated in the closed system, experiments were carried out according to condition 5 in Table 1. The result is shown by the solid lines in Figure 6, that is, the higher the heating temperature, the lower the equilibrium carbon content of the steel after heating. This implies that the carbon potential of the 
water-gas, generated in the closed system under a specific condition, decreases with increasing temperature of steel.

Amount of Carbon Carburized for the Steel Heated under the Water-Gas Atmosphere in the Closed System

Influence of the circulation rate of water-gas on the amount of carbon carburized. Experiments were conducted in the closed system according to condition 6 in Table 1, and the results are shown in Figures $7(a)$ and (b). The solid lines in Figure 7(a) indicate the relationship between heating time and the amount of carbon carburized per unit surface area for pure iron heated in water-gas with circulation rates of 120,260 , and $330 \mathrm{cc} / \mathrm{min}$. As can be seen from the plot, the carburized carbon of pure iron increases with increasing the circulation rate of water-gas. For low carbon steel SAE 1020 treated under identical conditions, a similar result was obtained as indicated by the solid lines in Figure 7(b).

Influence of charcoal temperature on the amount of carbon carburized. In order to compare the amount of carbon available for carburizing steel heated in the water-gas generated at various charcoal temperatures in the closed system, experiments were car-

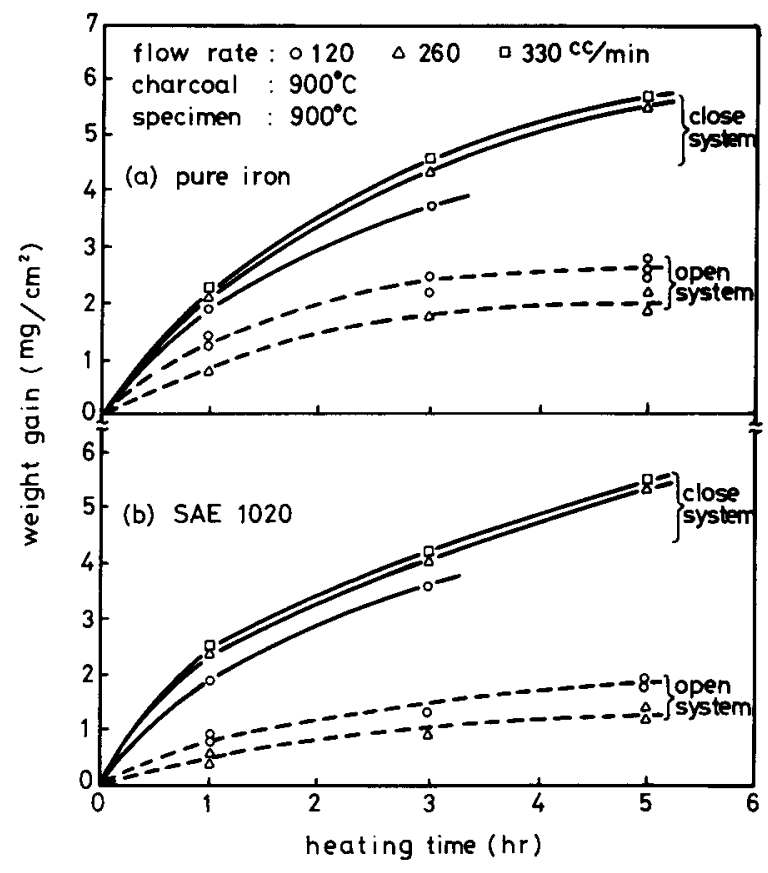

Fig. 7. Relationship between time and the weight gain per unit area due to carburization for (a) pure iron and (b) SAE 1020 heated in water-gas with various flow rates.

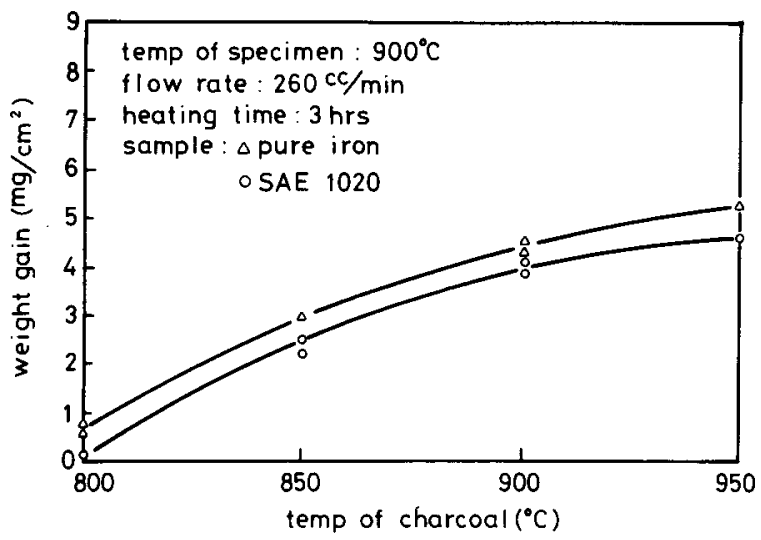

Fig. 8. Relationship between charcoal temperature and the weight gain per unit area for pure iron and SAE 1020 heated in the water-gas generated in the closed system.

ried out according to condition 7 in Table 1 . The result, shown in Figure 8, indicates that the weight of carbon available for carburizing per unit of surface area increases with increasing charcoal temperature. Furthermore, by comparing the weight gain per unit area for pure iron with that for low carbon steel, it is known that the total diffused carbon of pure iron is slightly greater than that of low carbon steel treated under the same conditions.

\section{Hardness Distribution in the Carburized Layer}

In order to understand the case hardness distribution for steel carburized in the water-gas atmosphere and quenched in water, experiments were performed according to condition 8 in Table 1. After being heated for a specific period of time in the water-gas atmosphere, the specimen was quenched into water. Then the disk shaped specimen was cut into two parts through the diameter with a low speed diamond saw. After the section was polished, the hardness of the surface layer was tested every $0.1 \mathrm{~mm}$ interval from the surface by a microhardness tester. The results are shown in Figures 9,10 and 11.

Figures 9(a) and (b) indicate the case hardness distribution for the carburized and water quenched pure iron treated in the closed system and open system, respectively. As shown in the plots, a longer carburizing time results in a harder case and a deeper case depth. By comparing the curves in Figure 9(a) with those in Figure 9(b), it is clear that the hardness of the case produced in the closed system is much higher than that produced in the open system for pure iron. A similar result was obtained for low carbon steel SAE 1020, as shown in Figures 10(a) and 


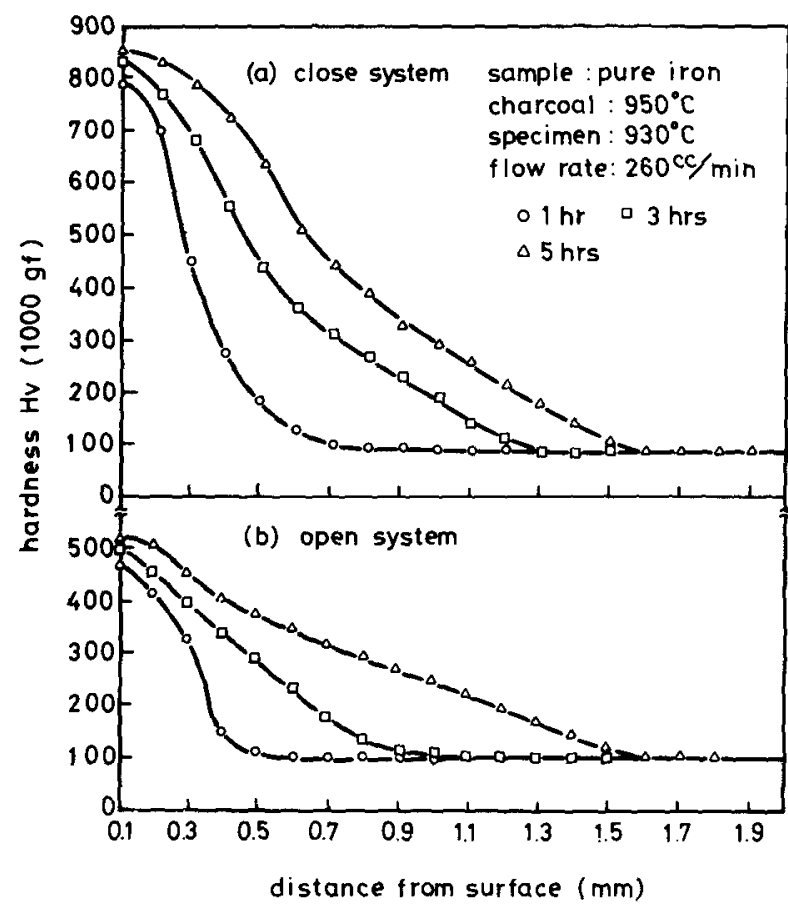

Fig. 9. Variation of case hardness with distance below the surface for pure iron heated at $930^{\circ} \mathrm{C}$ for various time under the water-gas atmosphere in (a) closed and (b) open systems, and followed by water quench.

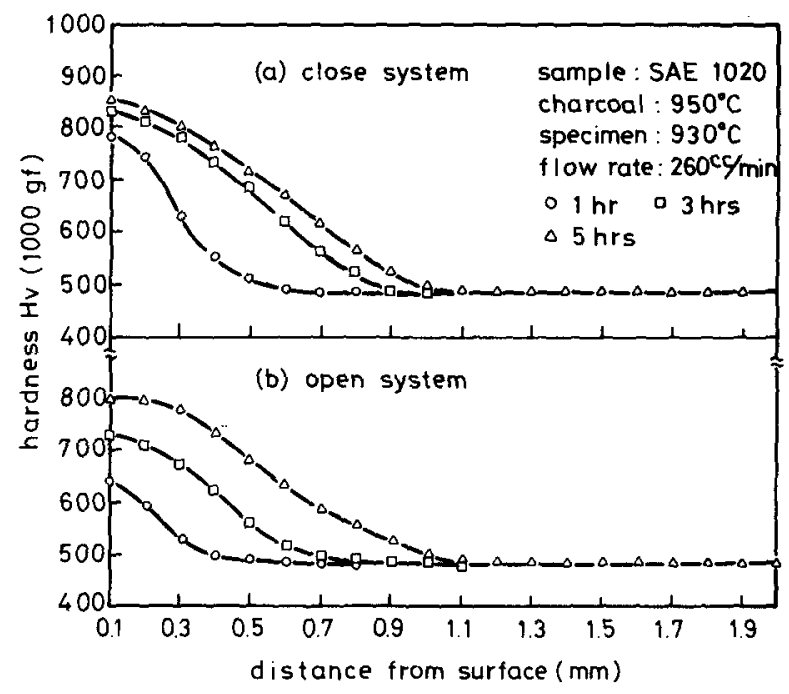

Fig. 10. Same as Fig. 9 except that the steel involved is low carbon steel SAE 1020.

(b). Figure 11(a) indicates the case hardness distribution for pure iron carburized for $3 \mathrm{hr}$ at $930^{\circ} \mathrm{C}$ in water-gas with various circulation rates. Comparing the two curves in the plot, we know that a greater circulation rate of water-gas results in a higher hard-

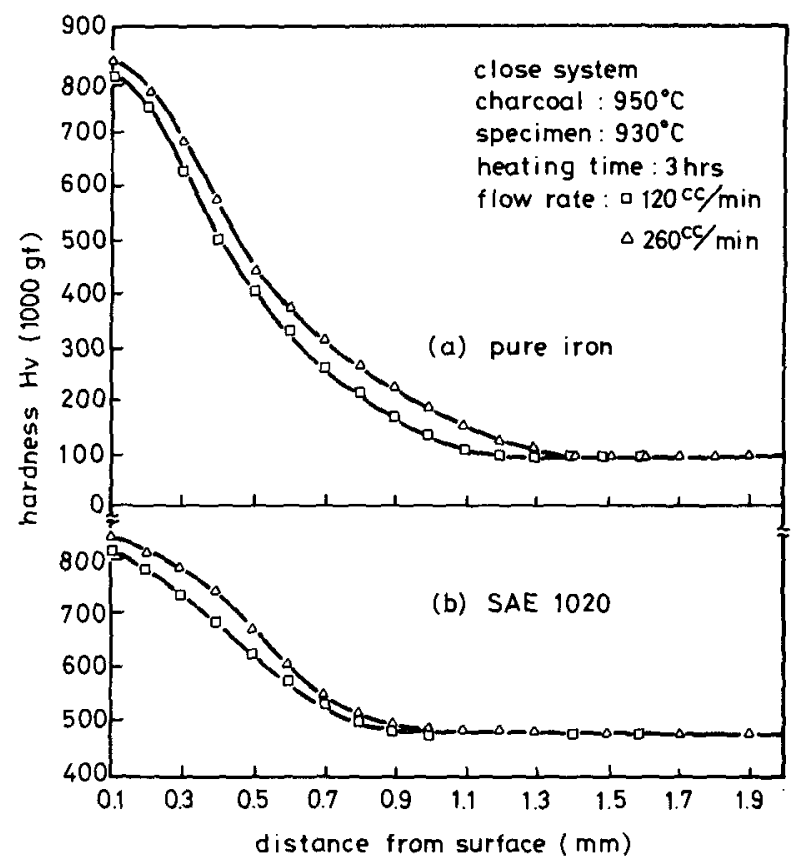

Fig. 11. Variation of case hardness with distance below the surface for (a) pure iron and (b) SAE 1020 heated at $930^{\circ} \mathrm{C}$ for $3 \mathrm{hr}$ under the water-gas atmosphere with various circulation rates in the closed system, and followed by water quench.

ness of the surface layer for pure iron. A similar result was also obtained for low carbon steel SAE 1020, as shown in Figure 11(b).

\section{Comparison of the Carburizing Result between the Closed System and Open System}

Comparison of the equilibrium carbon content. In order to compare the equilibrium carbon content of steel carburized in the closed system with that in the open system, experiments were conducted in both systems according to condition 3 in Table 1 . The equilibrium carbon content of SPCE carburized in the closed system is indicated by the solid lines in Figure 4, as mentioned previously. For example, the equilibrium carbon content of SPCE heated at $900^{\circ} \mathrm{C}$ is $1.05 \%$ when the circulation rate of water-gas is $120 \mathrm{cc} / \mathrm{min}$. However, that of SPCE carburized under identical conditions in the open system is only about $0.4 \%$, as indicated by the dashed line in Figure 4 . It can be concluded that the carbon potential of the water-gas generated in the closed system is much higher than that generated in the open system.

The dashed lines in Figure 6 indicate the result of the experiments conducted in the open system ac- 
cording to condition 5 in Table 1 . The heating temperatures of SPCE are $850^{\circ} \mathrm{C}, 900^{\circ} \mathrm{C}$, and $950^{\circ} \mathrm{C}$, and the corresponding equilibrium carbon contents are $0.73 \%, 0.52 \%$, and $0.42 \%$. Apparently, the higher the heating temperature of steel, the lower is its equilibrium carbon content. This tendency is similar to that in the closed system. However, comparing this result with that of the closed system, indicated by the solid lines in Figure 6 where the corresponding equilibrium carbon contents are $1.31 \%, 1.18 \%$, and $0.96 \%$, it is known that the specimen treated in the closed system reaches a higher equilibrium carbon content. This proves again that the carbon potential of the water-gas in the closed system is higher than that in the open system for the identical generation conditions.

Comparison of the amount of diffused carbon. In order to compare the amount of diffused carbon for steel heated under the water-gas atmosphere in the closed system with that in the open system, experiments were conducted in both systems according to condition 6 in Table 1 , and the results are shown in Figure 7, where the solid lines indicate the result for the closed system and the dashed lines for the open system. By comparing the solid lines and dashed lines in the figure, it is known that the amount of diffused carbon for the closed system is much greater than that for the open system. For example, at a charcoal temperature of $900^{\circ} \mathrm{C}$ and water-gas circulation rate of $260 \mathrm{cc} / \mathrm{min}$, the amounts of diffused carbon for pure iron and low carbon steel are $4.3 \mathrm{mg} / \mathrm{cm}^{2}$ and $4.0 \mathrm{mg} / \mathrm{cm}^{2}$, respectively after heating in the watergas at $900^{\circ} \mathrm{C}$ for $3 \mathrm{hr}$; however, under the identical conditions, except for heating in the open system, the amount of diffused carbon for pure iron and low carbon steel is just about $1.7 \mathrm{mg} / \mathrm{cm}^{2}$ and $1.0 \mathrm{mg} /$ $\mathrm{cm}^{2}$, respectively.

Comparison of the case hardness. In order to compare the hardness distribution of the case produced in the closed system with that produced in the open system, experiments were practiced in both systems according to condition 8 in Table 1 . For the convenience of comparison, the case hardness distribution curves for both systems were plotted in the same figure, as shown in Figure 12. Figure 12(a) indicates the case hardness distribution of the pure iron after $3 \mathrm{hr}$ of carburizing and water quenching. From the two curves in this figure, it is clear that the case hardness obtained in the closed system is much higher than that obtained in the open system. For example, at the point of $0.1 \mathrm{~mm}$ below surface, the former is HV 835; however, the latter is only HV 490 . Figure

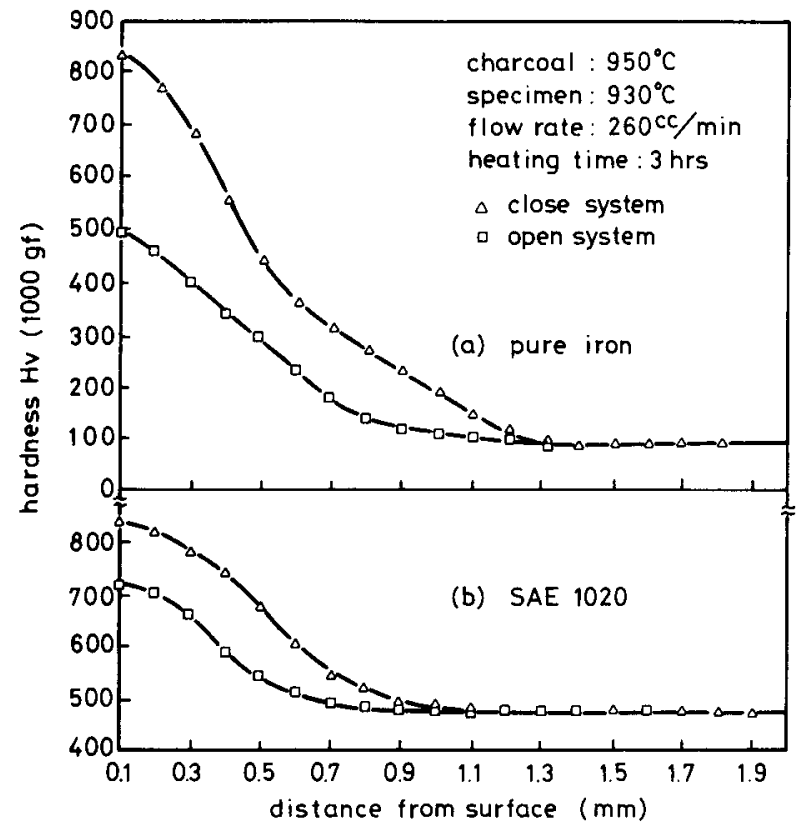

Fig. 12. Comparison between the case hardness distributions obtained in the closed and open systems for (a) pure iron and (b) SAE 1020 , heated at $900^{\circ} \mathrm{C}$ for $3 \mathrm{hr}$ under the water-gas atmosphere and followed by water quench.

12(b), the result for low carbon steel SAE 1020, also indicates that the case hardness obtained in the closed system is higher.

\section{Comparison of Charcoal Consumption between the Closed System and Open System}

In order to understand the consumption rate of charcoal for the closed system and open system, experiments were carried out in both systems according to condition 9 in Table 1 . The weight decrease of charcoal was recorded after generating a given amount of water-gas. The results are shown in Figure 13, where the horizontal axis denotes the volume of watergas at room temperature under $1 \mathrm{~atm}$, and the vertical axis denotes the consumption of charcoal. From this figure it is known that there is an approximately linear relationship between the charcoal consumption and the volume of water-gas generated for both systems.

For the open system, the slope of this line is 0.33 $\mathrm{g} / \mathrm{L}$; however, for the closed system, the slope of this line is $0.011 \mathrm{~g} / \mathrm{L}$. In other words, generating $1 \mathrm{~L}$ of water-gas in the open system needs $0.33 \mathrm{~g}$ of charcoal; however, generating $1 \mathrm{~L}$ of water-gas in the closed system needs only $0.011 \mathrm{~g}$ of charcoal, which is $1 / 30$ of that required in the open system. Clearly, 


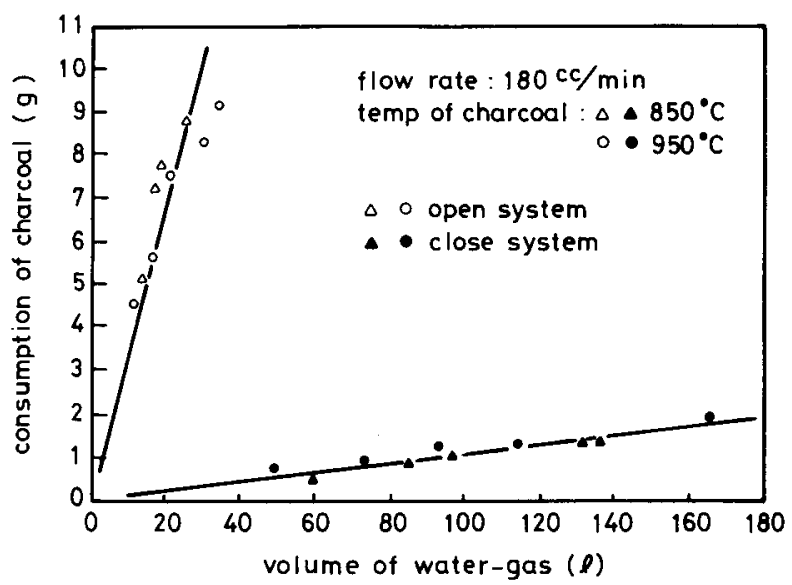

Fig. 13. Comparison of charcoal consumption for generating water-gas in the closed and open systems.

the closed system minimizes charcoal consumption in comparison with the open system.

\section{Discussion}

\section{Electromotive Force and Carburizing Capability of Water-Gas Atmospheres}

From the result in Figure 3(a), it is known that the EMF developed at the oxygen sensor for the watergas generated under a specific condition can remain unchanged for a long time. On the other hand, the EMF is closely related with the oxygen content and carbon potential of water-gas; that is, the higher the EMF, the lower the oxygen content and the higher the carbon potential of water-gas $[5,6]$. Thus, from Figure 3(a), it can be reasoned that the carburizing capability of water-gas during circulation is quite stable. This is consistent with the result of Figure 2. By comparing curves (1), (2) and (3) in Figure 3, it is known that the higher the charcoal temperature, the higher is the EMF of water-gas. In other words, water-gas generated from charcoal with a higher temperature possesses a higher carbon potential. This is consistent with the results of Figure 5 and Figure 8. In addition, by comparing the curves in Figure 3(a) with the corresponding ones in Figure 3(b), it is known that the EMF for the closed system is higher than that for the open system if charcoal temperatures for both systems are identical. It can be inferred that for the same charcoal temperature and the same generation rate, water-gas generated in the closed system possesses a higher carbon potential than that generated in the open system.
Relationship between Charcoal Temperature and the Carbon Potential of Water-Gas

Both Figures 5 and 8 indicate that the higher the charcoal temperature, the higher the carburizing capability of water-gas. As mentioned previously, the constituents of water-gas are $\mathrm{CO}, \mathrm{H}_{2}$, and small amounts of $\mathrm{CO}_{2}, \mathrm{H}_{2} \mathrm{O}, \mathrm{CH}_{4}$, etc. The higher the charcoal temperature, the higher the percentage of carburizing constituent, $\mathrm{CO}$, and the lower the percentage of decarburizing constituents, $\mathrm{CO}_{2}$ and $\mathrm{H}_{2} \mathrm{O}$, among the equilibrium constituents of water-gas [1], and accordingly, the higher the carbon potential of the water-gas atmosphere. The fact that the $\mathrm{CO}$ content increases and the $\mathrm{CO}_{2}$ content decreases with increasing charcoal temperature can be proved by the gas analysis data given in Table 2.

\section{Relationship between the Carburizing Capability and Generation Rate of Water-Gas}

The generation rate of water-gas influences a carburizing process two ways, namely, by affecting the flow velocity of water-gas and the residence time of water-gas in the charcoal layer. More precisely, the higher the generation rate of water-gas, the higher the velocity as it passes by the specimen, and the shorter its residence time in the charcoal layer. A rapid flow velocity for water-gas passing by the specimen favors a carburizing reaction; however, a short residence time in the charcoal layer will lower the carburizing capability of water-gas.

From the results of Figure 4, it is known that the equilibrium carbon content of a specimen carburized in the closed system increases with increasing the circulation rate of water-gas. The reason can be deduced as follows. When steel is carburized in watergas, decarburizing gases, $\mathrm{CO}_{2}$ and $\mathrm{H}_{2} \mathrm{O}$, will be generated by reactions (3) and (4). If these $\mathrm{CO}_{2}$ and $\mathrm{H}_{2} \mathrm{O}$ adhere on the surface of the steel, the subsequent carburizing reaction will be retarded because

Table 2. Chemical Composition of the Dehumidified Water-Gas Generated in the Closed System

\begin{tabular}{cccccc}
\hline \multirow{2}{*}{$\begin{array}{c}\text { Charcoal } \\
\text { Temp. } \\
\left({ }^{\circ} \mathrm{C}\right)\end{array}$} & $\begin{array}{c}\text { Generation } \\
\text { Rate }\end{array}$ & \multicolumn{4}{c}{ Chemical Composition (\%) } \\
\cline { 3 - 6 }$(\mathrm{cc} / \mathrm{min})$ & $\mathrm{CO}$ & $\mathrm{H}_{2}$ & $\mathrm{CO}_{2}$ & $\mathrm{CH}_{4}$ \\
\hline \multirow{2}{*}{950} & 120 & 50.53 & 48.34 & 0.14 & 0.98 \\
& 260 & 50.41 & 48.49 & 0.16 & 0.95 \\
900 & 120 & 49.46 & 48.63 & 0.60 & 1.30 \\
& 260 & 48.79 & 49.40 & 0.65 & 1.16 \\
850 & 120 & 47.20 & 50.49 & 1.08 & 1.22 \\
& 260 & 45.80 & 51.20 & 1.79 & 1.21 \\
\hline
\end{tabular}


Table 3. Chemical Composition of the Dehumidified Water-Gas Generated in the Open System

\begin{tabular}{cccccc}
\hline \multirow{2}{*}{$\begin{array}{c}\text { Charcoal } \\
\text { Temp. } \\
\left({ }^{\circ} \mathrm{C}\right)\end{array}$} & $\begin{array}{c}\text { Generation } \\
\text { Rate }\end{array}$ & \multicolumn{4}{c}{ Chemical Composition $(\%)$} \\
\cline { 4 - 7 }$(\mathrm{cc} / \mathrm{min})$ & $\mathrm{CO}$ & $\mathrm{H}_{4}$ & $\mathrm{CO}_{2}$ & $\mathrm{CH}_{4}$ \\
\hline \multirow{2}{*}{950} & 120 & 49.92 & 48.82 & 0.28 & 0.98 \\
& 260 & 49.04 & 49.61 & 0.31 & 1.03 \\
900 & 120 & 48.72 & 49.54 & 0.32 & 1.43 \\
& 260 & 48.66 & 49.06 & 0.85 & 1.43 \\
850 & 120 & 45.37 & 50.91 & 2.03 & 1.69 \\
& 260 & 39.44 & 54.42 & 4.44 & 1.69 \\
\hline
\end{tabular}

the carbon potential of the atmosphere near the surface of the steel will decrease owing to the accumulation of $\mathrm{CO}_{2}$ and $\mathrm{H}_{2} \mathrm{O}$. The furnace atmosphere with a high flow velocity tends to remove the $\mathrm{CO}_{2}$ and $\mathrm{H}_{2} \mathrm{O}$ from surface of the steel, and avoids the subsequent decrease of carbon potential. Thus, for the atmosphere with a definite composition, the greater the flow rate, the higher the equilibrium carbon content of steel after heating in it. Moreover, when the flow rate of an atmosphere increases, the collision frequency between steel and the atmosphere will increase; consequently, the amount of carbon carburized per unit area of the steel will increase as well. This point is illustrated by the solid lines in Figure 7.

The dashed lines in Figure 7 indicate that increasing the generation rate of water-gas in the open system will result in a decrease of carburized carbon of steel. This is because the water-gas in the open system is generated by reacting water vapor with hot charcoal, and it takes more time to complete this reaction. If the residence time of water vapor in the charcoal layer is insufficient, the percentages of decarburizing constituents, $\mathrm{CO}_{2}$ and $\mathrm{H}_{2} \mathrm{O}$, in the watergas will increase markedly. As a result, the carburizing capability of water-gas will decrease. This can be proved by the data of gas analysis given in Table 3 .

\section{Carburizing Results for the Closed System and Open System}

All the results in Figures 9, 10, and 12 indicate that the hardness of the carburized and hardened case treated in the closed system is higher than that treated in the open system. Because the water-gas generated in the closed system possesses a higher carburizing capability, as reasoned previously, the carbon content of the case produced in the closed system is higher as well. After quenching, the microstructure of the case is mainly martensite, the hardness of which increases with increasing carbon content. Thus, the hardness of the case produced in the closed system is higher. From this it can be concluded that the result of carburizing conducted in the closed system is superior to that in the open system.

\section{Relationship between the Chemical Composition and Carbon Potential of Water-Gas}

Water-gas may be regarded as an $\mathrm{H}_{2}+\mathrm{CO}+\mathrm{CO}_{2}$ $+\mathrm{H}_{2} \mathrm{O}+\mathrm{CH}_{4}$ gas mixture. Its carbon potential is proportional to the value of $P_{\mathrm{CO}}^{2} / P_{\mathrm{CO}_{2}}[1,5,6]$, where $P_{\mathrm{CO}}$ and $P_{\mathrm{CO}_{2}}$ denote the partial pressure of $\mathrm{CO}$ and $\mathrm{CO}_{2}$, respectively. Tables 2 and 3 present the chemical composition of the dried water-gas generated under various conditions in the closed system and open system, respectively. From the two tables, it is known that the higher the charcoal temperature, the higher the $\mathrm{CO}$ content and the lower the $\mathrm{CO}_{2}$ content for the water-gas generated at a definite generation rate. In other words, the rise of charcoal temperature will increase the value of $P_{\mathrm{CO}}^{2} / P_{\mathrm{CO}_{2}}$, and consequently increase the carbon potential and carburizing capability of the water-gas generated. This is consistent with the results of Figures 5 and 8. Moreover, by comparing the corresponding data in Table 2 and Table 3, it can be found that for the same charcoal temperature and the same generation rate, watergas generated in the closed system contains more $\mathrm{CO}$ and less $\mathrm{CO}_{2}$ than that generated in the open system. Thus, the former possesses a higher carbon potential than the latter. In addition, if the temperature of charcoal keeps constant, increasing the generation rate of water-gas will decrease the volume percentage of $\mathrm{CO}$ and increase the volume percentage of $\mathrm{CO}_{2}$, and accordingly lower the value of $P_{\mathrm{CO}}^{2} / P_{\mathrm{CO}_{2}}$, for both systems. However, the decrease in the value of $P_{\mathrm{CO}}^{2} / P_{\mathrm{CO}_{2}}$, for the open system is more serious than that for the closed system. This implies that increasing the circulation rate of water-gas in the closed system does not affect the chemical composition and carbon potential so much. For this reason, when the circulation rate of water-gas increases, the positive effect on carburizing due to the increase in its flow velocity probably exceeds the negative effect on carburizing due to the slight change in its chemical composition. Thus, if the circulation rate of water-gas increases, both the equilibrium carbon content and the amount of carbon carburized per unit area of steel will increase as well. The solid lines in Figure 4 and Figure 7 indicate this situation.

On the other hand, increasing the generation rate 
of water-gas in the open system will lower its carbon potential pronouncedly owing to the marked change of its chemical composition. For this reason, when the generation rate of water-gas increases, the positive effect on carburizing due to the increase in its flow velocity can't offset the negative effect due to the change in its chemical composition. Thus, for the open system, when the generation rate of water-gas increases, the amount of carbon carburized per unit area of steel decreases, as indicated by the dashed lines in Figure 7.

\section{Consumption of Charcoal}

From Figure 13, it is known that the consumption of charcoal for generating a given amount of water-gas in the closed system is far smaller than that for generating the same amount of water-gas in the open system.

In the open system, the main reaction for generating water-gas is as follows:

$$
\mathrm{H}_{2} \mathrm{O}+\mathrm{C} \rightarrow \mathrm{H}_{2}+\mathrm{CO}
$$

That is, one mole of carbon reacting with water vapor will produce two moles of water-gas. One mole of carbon weighs $12 \mathrm{~g}$ and the volume of two moles of water-gas is about $49 \mathrm{~L}$ at room temperature under $1 \mathrm{~atm}$. Calculating from these data, we know that $0.24 \mathrm{~g}$ of carbon is needed to produce 1 $\mathrm{L}$ of water-gas by reacting carbon with water vapor. However, by experiment, $0.33 \mathrm{~g}$ of charcoal is consumed to generate $1 \mathrm{~L}$ of water-gas in the open system. The experimental value is greater than the calculated value because charcoal is not pure carbon, but also contains moisture, ash, and other impurities.

As stated in the introduction, the water-gas of the closed system is generated by reacting the used water-gas from the specimen furnace with hot charcoal. In the specimen furnace, the main reactions are the carburizing reactions of Eqs. (3) and (4), whereas in the charcoal furnace, the main reactions are the carbon potential recovering reactions of Eqs. (1) and (5). During carburizing, these reactions repeat unceasingly. Thus, water-gas may be regarded as a carrier gas of carbon, which carries carbon from charcoal to steel. Theoretically, the weight decrease of charcoal should be equal to the weight increase of steel due to carburizing, if one neglects the soot formed in furnaces and the impurities contained in charcoal. Therefore, the charcoal consumption in the closed system is minimal compared with that in the open system.

\section{Conclusions}

1. The carburizing capability of water-gas atmospheres in a closed circulative system is rather stable. For a definite charcoal temperature and a given circulation rate, the carbon potential of the water-gas can remain unchanged for a long period of time.

2. The equilibrium carbon content of steel heated under the water-gas atmosphere in the closed system depends on the temperatures of steel and charcoal, and the circulation rate of water-gas. If both the temperature of charcoal and the circulation rate of water-gas keep unchanged, the higher the heating temperature of steel, the lower its equilibrium carbon content after heating in the water-gas. If the heating temperature of the steel keeps constant, either increasing the temperature of charcoal or increasing the circulation rate of water-gas will result in an increase in the equilibrium carbon content of the steel.

3 . If both the temperature of charcoal and the generation rate of water-gas are definite, the watergas generated in the closed system possesses a higher carbon potential than that generated in the open system.

4. The hardness of the carburized and hardened case obtained in the closed system is higher than that obtained in the open system under the same conditions.

5. Carburizing of steel by using water-gas atmospheres in a closed system can (a) avoid the air pollution caused by the exhausted atmosphere, (b) markedly economize the raw material for preparing the atmosphere (charcoal consumption rate cut by about $97 \%$ for the apparatus used in this experiment) and (c) get a better carburizing result.

Acknowledgments. The authors wish to acknowledge the National Science Council of Taiwan, R.O.C. for the financial support for this research under grant No. NSC-790401-E002-17. In addition, particular thanks are due to Professor C. H. Hwang for his continued advice and encouragement.

\section{References}

1. Y.C. Chen and C.H. Hwang: Heat Treatment of Metals, 1984, No. 4, pp. 96-101.

2. Y.C. Chen, K.C. Chi, and C.H. Hwang: Chinese Jour- 
nal of Materials Science, 1987, Vol. 19, No. 4, pp. 262278.

3. Y.C. Chen, C.C. Wu, and C.H. Hwang: Chinese Journal of Materials Science, 1989, Vol. 21, No. 1, pp. 4559.

4. Y.C. Chen, B.S. Yu, and C.H. Hwang: Chinese Journal of Materials Science, 1989, Vol. 21, No. 3, pp. 169181.
5. M.J. Bannister: Industrial Heating, March 1984, pp. 24-26.

6. F.E. Harris: Metal Progress, January, 1945, Vol. 47. No. 1, pp. 84-89.

Received September 27, 1991. 